NBER WORKING PAPER SERIES

SECTORIAL WAGES AND

THE REAL EXCHANGE RATE

Joshua Aizenman

Jacob A. Frenke 1

Working Paper No. 1801

NATIONAL BUREAU OF ECONOMIC RESEARCH

1050 Massachusetts Avenue

Cambridge, MA 02138

January 1986

An earlier version of this paper was presented at a Conference on The Foreign Exchange Rate in Inflation and Stabilization, sponsored by the Aron and Michae 1 Chilewich Chair in International Economics at the Hebrew University of Jerusalem, Israel, June 2-3, 1985. We wish to acknowledge helpful comments by Elhanan Helpman. The research reported here is part of the NBER's research programs in Economic Fluctuations and International Studies. Any opinions expressed are those of the authors and not those of the National Bureau of Economic Research. 


\section{Sectorial Wages and the Real Exchange Rate}

\section{ABSTRACT}

Consider a multi-sector economy subject to an exogenous demand shock that alters the equilibrium structure of relative prices. How should the structure of sectorial wages adjust in response to such a shock? This question is addressed in the context of a multi-sector model of an openeconomy producing internationally tradable and non-tradable goods. In order to focus on intersectorial wage structure without abandoning the competitive neoclassical paradigm we assume that workers differ from each other in their absolute and relative skills. Such differences result in equilibrium wage differentials which are affected by the exogenous real shock. Cost of negotiations result in labor market contracts which set nominal wages in advance of the realization of the stochastic shocks. The analysis provides formulae for the optimal sectorial wage-indexation rules. The optimal rules alter both the absolute and the relative structure of sectorial nominal wages. We examine the dependence of the optimal wage adjustments on the degree of heterogeneity of the skill distribution and on the degree to which the economy is open to international trade; we also study the effects of various shocks and policies on the real exchange rate, real wages and the distribution of income.

Joshua Aizenman

Graduate School of Business

University of Chicago

1101 E. 58 th Street

Chicago, IL 60637

(312) $962-7260$
Jacob A. Frenkel

Department of Economics

University of Chicago

1126 E. 59th Street

Chicago, IL 60637

(312) $962-8253$ 
Consider a multi-sector economy subject to an exogenous demand shock that alters the equilibrium structure of relative prices. How should the structure of sectorial wages adjust in response to such a shock? General equilibrium analysis since the classic article by Stolper and Samuelson (1941) has clarified the equilibrium relation between commodity and factor prices for an economy in which factors of production are fully mobile among sectors and factor returns are fully flexible. This analysis has been extended to situations in which factor mobility is limited (e.g. Jones (1971), Mayer (1974) and Mussa (1974)) and factor rewards are rigid (e.g. Brecher (1974), helpman (1977), Johnson (1965) and Neary (1980)). In these studies the labor force is assumed to be homogeneous and, therefore, labor mobility ensures that wages per worker are equalized across sectors. In practice, however, the labor force is likely to be heterogeneous since the relative skills of workers are not the same. The dissimilarities among workers result in equilibrium intersectoral wage differentials. With heterogeneous workers real shocks call for differential adjustments of sectorial wages.

In this paper we address the question of how should sectorial wages be adjusted in response to exogenous shocks when the labor force is heterogeneous. In order to conform with stylized facts we assume that in the short-run wages are governed by wage contracts. The economy produces tradable and non-tradable goods and is assumed to be "small" so that it is a price taker in the world market for tradable goods. In order to focus on the intersectorial wage structure without abandoning the competitive neoclassical paradigm, we assume that workers differ from each other in their absolute and relative skills. Such differences result in an equilibrium intersectorial wage differentials. In modelling the distribution of skills we adopt the formulation suggested by Rosen (1978) and applied by Mussa (1982b). In addition, we allow for labor-market contracts according to which nominal wages are set in advance of the realization of the stochastic shocks. As 
in Gray (1976) and Fischer (1977), this labor-market convention reflects the cost of negotiations and results in some short-run stickiness of nominal wages. This short-run stickiness impacts on resource allocation and imposes welfare cost. The main purpose of our analysis is to provide formulae for the differential sectorial wage adjustment which reduces (or even nullifies) the undersirable effects of this stickiness. The formulae may be viewed as policy rules for sectorial wage indexation or, alternatively, as characteristics of optimal sectoral wage contracts. The key difference between the conventional analysis of optimal wage indexation and ours is that the conventional analysis is conducted within a one-sector model with homogeneous labor whereas ours is conducted within a multi-sector model with heterogeneous labor. As a result in our framework exogeneous shocks to aggregate demand call for adjustments of both absolute and the relative wages.

The formal model is outlined in section I which specifies the supply of output, the employment of labor and private and government demands. Section II provides the solution of the model for the intermediate run -- a run during which all wage contracts can be renegotiated and wages are flexible. In this context we determine the equilibrium values of the real exchange rate the level of output and sectorial real wages consequent on an exogenous change in aggregate demand for domestic goods. Section III provides the corresponding solution of the model for the short run during which wages are given by the prevailing labor-market contracts. It is shown that an important factor underlying the short-run consequences of changes in aggregate demand is the accompanying nominal exchange rate policy. The main contribution of the paper is contained in section IV. There, we provide the precise optimal nominal-wage rules necessary for the simultaneous attainment of the undistorted equilibrium relative and absolute sectorial wages and resource allocation. In this context we examine the dependence of the wage adjustment formulae on the degree of heterogeneity of the distribution of relative 
skills and on the degree to which the economy is open to international trade. Finally, section $V$ contains concluding remarks. The paper is followed by an Appendix that examines the impact of the changes in aggregate demand on the distribution of income in the short run and in the long run.

\section{The Model}

In this section we outline the building blocks of the model. These building blocks contain a specification of the supply, including an analysis of the factors determining the levels of commodity output and labor input, and a specification of the demand.

The economy is assumed to produce two classes of goods: tradables, $x_{T}$, and non-tradables, $x_{N}$, using linear homogenous production functions. We adopt the specific-factor model of Jones (1971), Mussa (1974) and Mayer (1974). In that model each sector is assumed to employ factors of production that are sectorspecific and are immobile across sectors. The production functions are

$$
X_{T}=x_{T}\left(L_{T}\right)
$$

(1)

$$
\mathrm{X}_{\mathrm{N}}=\mathrm{X}_{\mathrm{N}}\left(\mathrm{L}_{\mathrm{N}}\right)
$$

where $L_{T}$ and $L_{N}$ denote, respectively, labor services used in producing tradeable and non-tradable goods. The marginal product of labor is assumed to be positive and diminishing, and we suppress the specific factors in the formulation of the production functions.

In order to have a meaningful analysis of intersectorial wage structure, we adopt a formulation suggested by Rosen (1978) and applied by Mussa (1982b) 
according to which workers differ in their skills. The transformation between $L_{T}$ and $\mathrm{L}_{\mathrm{N}}$ reflects the assumption that the relative skills of workers in producing the various commodities are not the same. Figure 1 motivates the argument. Let the skills of the $i^{\text {th }}$ worker be such that his labor services per unit of time of employment in the tradable goods sector are $\mathrm{L}_{\mathrm{T}}^{i}$, and his labor services per unit of time of employment in the non-tradable goods sector are $\mathrm{L}_{\mathrm{N}}^{i}$. The skills of each worker can be represented in Figure $q$ by a given point. Thus, point $\underline{a}$ indicates that worker $\underline{A}$ provides $\mathrm{L}_{\mathrm{T}}^{\mathrm{a}}$ labor services if employed in the tradable goods sector, and $\mathrm{L}_{\mathrm{N}}^{\mathrm{a}}$ if employed in the non-tradable goods sector. Each worker in the economy is represented by a point in Figure 1. Accordingly, point $\underline{b}$ corresponds to worker $\underline{B}$ whose relative skills are more appropriate for the production of tradable goods. The allocation of workers between sectors is determined by the relative intersectorial wages. Wages per unit of labor services in the tradable and the non-tradable goods sectors are denoted by $\mathrm{W}_{\mathrm{T}}$ and $\mathrm{W}_{\mathrm{N}}$, respectively. If the wage ratio is $\left(\mathrm{W}_{\mathrm{N}} / \mathrm{W}_{\mathrm{T}}\right)_{\mathrm{O}}$, then each worker $i$ whose productivity ratio, $\left(\mathrm{L}_{\mathrm{T}}^{i} / \mathrm{L}_{\mathrm{N}}^{i}\right)$, exceeds the wage ratio (like worker $\underline{B}$ ) will prefer employment in the tradable goods sector, and each worker whose productivity ratio falls short of the given wage ratio (like worker $\underline{A}$ ) will prefer employment in the non-tradable goods sector. Marginal workers whose productivity ratio coincide with the wage ratio (like worker $\underline{C}$ ) will be indifferent as to the sector of employment. The given wage ratio is associated with a given intersectoral allocation of employment. The supply of labor services to the non-tradable goods sector, $\mathrm{L}_{\mathrm{N}}$, is the sum of the labor services of all workers whose productivity ratio $\left(L_{T}^{i} / L_{N}^{i}\right)$ is smaller than the wage ratio $\left(\mathrm{W}_{\mathrm{N}} / \mathrm{W}_{\mathrm{T}}\right)_{0}$. Analogously, $\mathrm{L}_{\mathrm{T}}$ is the sum of the labor services provided by the workers whose productivity ratio $\left(\mathrm{L}_{\mathrm{T}}^{i} / \mathrm{L}_{\mathrm{N}}^{i}\right)$ exceed the given wage ratio. In the subsequent discussion we will refer to $\mathrm{L}_{\mathrm{N}}$ and $\mathrm{L}_{\mathrm{T}}$ as the supply of labor provided to the two sectors. This supply is measured in units of labor services rather 


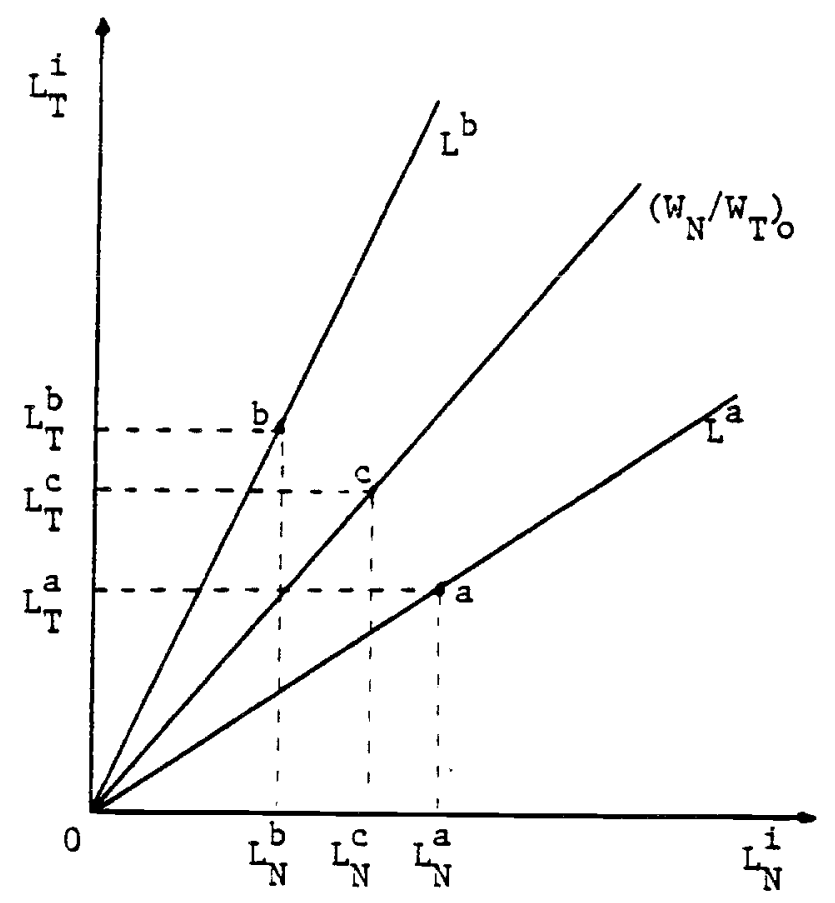

Figure 1: Relative Skills of Labor and the Wage Ratio. 
than number of workers. ${ }^{1}$ To each and every wage ratio, $\left(W_{N} / W_{T}\right){ }_{0}$, corresponds an allocation $\left(\mathrm{L}_{\mathrm{T}} / \mathrm{L}_{\mathrm{N}}\right)_{0}$. The set of possible allocations defines a labor transformation function according to which

$$
\mathrm{L}_{\mathrm{T}}=\mathrm{L}_{\mathrm{T}}\left(\mathrm{L}_{\mathrm{N}}\right)
$$

The labor transformation function is shown in Figure 2. Its slope at each point is the productivity ratio of the marginal workers. For a marginal worker who is represented by point $\subseteq$ in Figure 1, the productivity ratio, $\mathrm{L}_{\mathrm{T}}^{\mathrm{C}} / \mathrm{L}_{\mathrm{N}}^{\mathrm{C}}$, equals the wage ratio $\left(W_{N} / W_{T}\right)_{0}$. Thus, the slope of the labor transformation function at the equilibrium intersectorial allocation of labor, $L_{T}^{\circ}$ and $L_{N}^{\circ}$, is the wage ratio. In terms of Figure 2, this allocation is represented by point $A_{0}$ at which the slope of the labor transformation function is $\left(W_{N} / W_{T}\right)_{0}{ }^{\circ}$ This relation implies that

$$
\frac{d L_{T}}{d L_{N}}=-\frac{W_{N}}{W_{T}}
$$

The wage ratio which determines the allocation of labor and, thereby, the level of production is uniquely related to the relative price of the final goods. Specifically, profit maximization requires that the wage in each sector equals the value of the marginal product of labor. Thus,

$$
\frac{\mathrm{W}_{\mathrm{N}}}{\mathrm{W}_{\mathrm{T}}}=\frac{\left(\partial \mathrm{X}_{\mathrm{N}} / \partial \mathrm{L}_{\mathrm{N}}\right)}{\left(\partial \mathrm{X}_{\mathrm{T}} / \partial \mathrm{L}_{\mathrm{T}}\right)}\left(\frac{\mathrm{P}_{\mathrm{N}}}{\mathrm{P}_{\mathrm{T}}}\right)
$$

Equations (3) and (4) imply that in equilibrium,

$$
\frac{\mathrm{dL}_{\mathrm{T}}}{\mathrm{dL}_{\mathrm{N}}}=-\frac{\left(\partial \mathrm{X}_{\mathrm{N}} / \partial \mathrm{L}_{\mathrm{N}}\right)}{\left(\partial \mathrm{X}_{\mathrm{T}} / \partial \mathrm{L}_{\mathrm{T}}\right)}\left(\frac{\mathrm{P}_{\mathrm{N}}}{\mathrm{P}_{\mathrm{T}}}\right)
$$




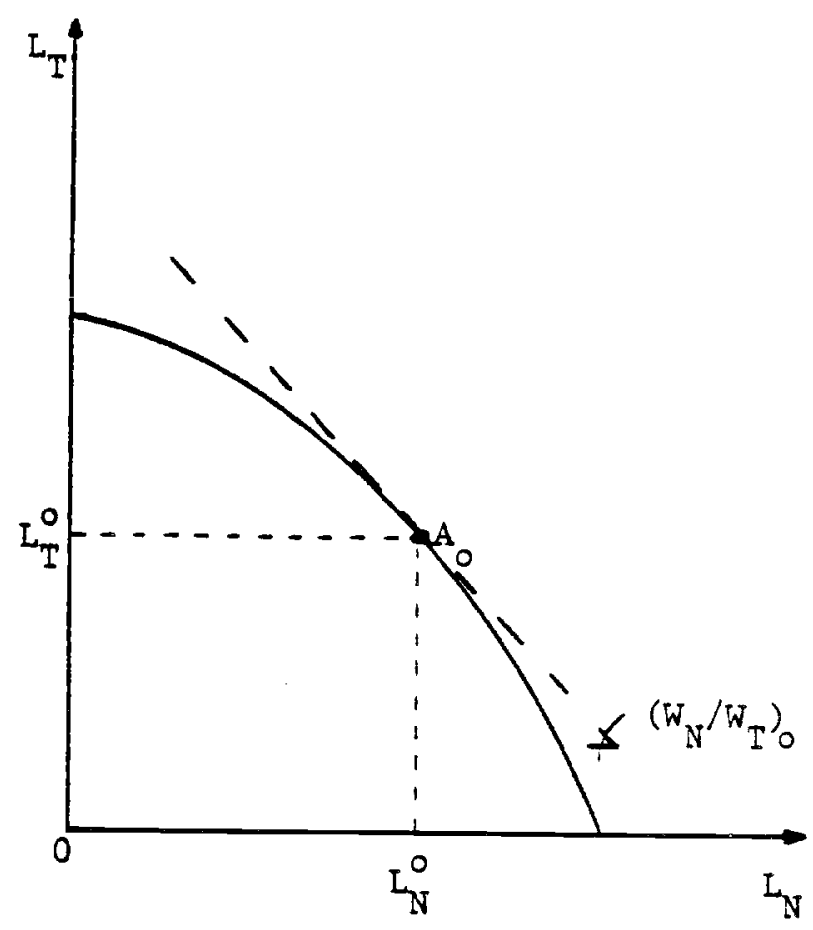

Figure 2: The Labor Transformation Function. 
Taking the logarithmic derivatives of (5), expressing in terms of elasticities and denoting the percentage change in the amount of labor services employed in the non-tradable goods sector by $\ell_{N}$, yields

$$
\ell_{N}=-\frac{q}{n_{N}+n_{T}+\frac{1}{\theta}}
$$

An analogous expression can be obtained for $\ell_{T^{--t h e ~}}$ percentage change in the amount of labor services employed in the tradable goods sector. In equation (6), $q$ denotes the percentage change in the real exchange rate, $\left(P_{T} / P_{N}\right)--, \eta_{N}$ and $\eta_{T}$ denote the (absolute values of the) elasticities of the marginal products of labor in the two sector with respect to labor services employed in producing nontradable goods, and $\theta$ denotes the (absolute value of the) elasticity of labor services employed in the production of non-tradable goods with respect to the wage ratio; thus $\theta=-\operatorname{dlog} L_{N} / d \log \left(W_{N} / W_{T}\right)$. Since in equilibrium along the labor transformation function in Figure 2 the wage ratio equals $-\mathrm{dL}_{\mathrm{T}} / \mathrm{dL}_{\mathrm{N}}$, it follows that $\theta$ measures the elasticity of $\mathrm{L}_{\mathrm{N}}$ along the labor transformation function. When the relative skills of all workers are the same the elasticity of the labor transformation function is infinite and the schedule in Figure 2 becomes a straight Iine. The larger the difference in the relative skills of different workers the smaller is $\theta$ and the larger is the curvature of the labor transformation function.

In the subsequent analysis we examine the effects of disturbances on the equilibrium of the short run and the intermediate run. We define the length of the run in terms of the degrees of nominal wage flexibility and intersectorial labor mobility. Thus, the short run is defined as the run during which nominal wages are given by labor contracts; the intermediate run is defined as the run during which nominal wages are flexible but the distribution of relative skills is 
given. Therefore, in the intermediate run workers are mobile between sectors subject to the labor transformation function of Figure $2 .^{2}$

The expression in equation (6) provides the link between the real exchange rate and the amount of labor services employed in the non-tradable goods sector or, more precisely, the link between the percentage changes in these variables. This, together with the definition of $\theta$, provides the link between the real exchange rate $q$ and the wage ratio. In order to find the corresponding levels of output we note that equations (1) and (2) define the economy's production possibilities frontier. This frontier embodies the considerations underlying the labor transformation function. ${ }^{3}$

The private sector's demand for non-tradable goods, $D_{N}$, is assumed to be a positive function of the real exchange rate, $P_{T} / P_{N}$, and of real wealth, $V .4$ Thus,

$$
D_{N}=D_{N}\left(\frac{P_{T}}{P_{N}}, V\right)
$$

The private demand for tradable goods, $D_{T}$, can be represented by an analogous function except that a $r$ ise in the real exchange rate is presumed to lower the demand. Government demands for the two goods are denoted by $G_{N}$ and $G_{T}$. The subsequent analysis focuses on the adjustment of the economy to exogenous shocks to aggregate demand. These shocks may arise from either an exogenous change in private-sector wealth that impacts on aggregate demand, or from a change in the level and composition of government spending. 
II. Equilibrium Real Exchange Rate and Real Wages: The Intermediate Run

In equilibrium the demand for non-tradable goods must equal the supply. On the other hand differences between the demand and the supply for tradable goods are reflected in the current account of the balance of payments. In this section we determine the intermediate-run equilibrium adjustment of the real exchange rate and of the sectorial real wages. These solutions provide the benchmark for the analysis in section IV in which we determine optimal short-run policies.

\section{II.1 The Real Exchange Rate}

In specifying the equilibrium in the non-tradable goods sector it is convenient to start with the intermediate run during which nominal wages are flexible. Equilibrium in the non-tradable goods market requires that

$$
G_{N}+D_{N}\left(\frac{P}{P_{N}}, V\right)=x_{N}\left(\frac{P_{T}}{P_{N}}\right)
$$

In order to analyse the effects of exogenous shocks on the equilibrium real exchange rate, we differentiate equation (8) logarithmically and, denoting by lower case letters the percentage change of a variable from its initial (pre-shock) equilibrium value yields

$$
\lambda_{N}^{g} g_{N}+\lambda_{N}^{p}[\xi q+v]=x_{N}(q)
$$

where $\lambda_{N}^{g}$ and $\lambda_{N}^{p}=\left(q-\lambda_{N}^{8}\right)$ are the relative shares of government and private sectors demands for non-tradable goods in total demand. In equation ( 9 ) $\mathrm{g}_{\mathrm{N}}, \mathrm{v}, \mathrm{x}_{\mathrm{N}}$ and $\mathrm{q}$ denote the percentage change in government spending, private wealth, the output of non-tradable goods and the real exchange rate, respectively, and $\xi$ denotes the 
elasticity of the demand with respect to the real exchange rate. The formulation of (9) also assumes a unitary elasticity of demand with respect to wealth.

Equation (9) can also be written in an alternative and more useful way. First, its right-hand side can be expressed in terms of the corresponding changes in labor input. Thus, using the production function,

$$
x_{N}(q)=\beta_{N} l_{N}(q)
$$

where $B_{N}$ denotes the elasticity of output of the non-tradable goods with respect to labor input. Second, the left-hand-side of equation (9) can be decomposed into terms involving direct changes in demand and terms which reflect indirect changes that are induced by changes in the real exchange rate. We denote the direct (exogeneous) changes in demand for non-tradable goods by $\psi$, where

$$
\psi=\lambda_{\mathrm{N}}^{\mathrm{g}} \mathrm{g}_{\mathrm{N}}+\lambda_{\mathrm{N}}^{\mathrm{p}} \mathrm{v}
$$

Using equations (6) and (10), we can express equation (9) as .

$$
\psi+\lambda_{N}^{p} \xi q=-\frac{{ }_{N}{ }^{q}}{\eta_{N}+\eta_{T}+\frac{1}{\theta}}
$$

Finally, solving for the equilibrium real exchange rate (or more precisely the percentage change thereof) yields

$$
q=-\frac{\psi}{\frac{\beta_{N}}{n_{N}+\eta_{T}+(q / \theta)}+\lambda_{N}^{p} \xi} \text {. }
$$


Equation (12) expresses the equilibrium real exchange rate as a function of the exogenous shock to the demand for non-tradable goods, $\psi$, and the key parameters. For example, a rise in the demand for non-tradable goods, induced by an exogenous $r$ ise in government spending or by an exogenous rise in private sector wealth (a positive $\psi$ ), lowers $q$. The fall in $q$ is smaller the higher is $B_{N}^{--t h e ~ e l a s-~}$ ticity of non-tradable goods output with respect to the input of labor, and the higher is $\lambda_{\mathrm{N}}^{\mathrm{p}}$--the relative share of private sector's demand in total demand for non-tradable goods. Likewise, the fall in $q$ is larger the higher are $\eta_{N}$ and $\eta_{T}^{--}$ the (absolute values of the) elasticities of the marginal products of labor with respect to the employment of labor services in the non-tradable goods sector. The fall in $q$ depends on the magnitude of the elasticity of the labor transformation function. The higher the value of $\theta$ the smaller the decline in $q$.

\section{II.2 Sectorial Wages}

The product wage in each sector $\left(\mathrm{W}_{\mathrm{N}} / \mathrm{P}_{\mathrm{N}}\right.$ and $\left.\mathrm{W}_{\mathrm{T}} / \mathrm{P}_{\mathrm{T}}\right)$ equals the corresponding marginal product of labor. Therefore, the percentage change in the product wages $\left(w_{N}-p_{N}\right.$ and $\left.w_{T}-p_{T}\right)$ are $-n_{N} \ell_{N}$ and $n_{T} \ell_{N}$. We can use equation (6) for $l_{N}$ and obtain equations (13) and ( 14 ) as the elasticities of the sectorial product wages with respect to the real exchange rate:

$$
\frac{w_{N}-p_{N}}{q}=\frac{n_{N}}{n_{N}+n_{T}+\frac{1}{\theta}}>0
$$

$$
\frac{w_{T}-p_{T}}{q}=\frac{-n_{T}}{n_{N}+n_{T}+\frac{1}{\theta}}<0
$$


Thus, a rise in the real exchange rate raises the product wage in the non-tradable goods sector and lowers the product wage in the tradable goods sector. The absolute values of these elasticities are higher the higher is the value of $\theta$. In the extreme case with $\theta=0$ the product wage does not change in response to changes in the real exchange rate.

In order to find the effects of changes in the real exchange rate on the real wage in terms of the consumption basket (henceforth the consumption wage) we first define the consumer price index as a Cobb-Douglas function of the nominal prices of tradable and non-tradable goods. Accordingly, $p=\alpha_{N} p_{N}+\alpha_{T} p_{T}, \alpha_{N}$ and $\alpha_{T}=1-\alpha_{N}$ are the corresponding expenditure shares. Hence, in the non-tradable goods sector

$$
w_{N}-p=w_{N}-p_{N}-\left(p-p_{N}\right)=w_{N}-p_{N}-\alpha_{T} q,
$$

and, in the tradable goods sector

$$
w_{T}-p=w_{T}-p_{T}-\left(p-p_{T}\right)=w_{T}-p_{T}+\alpha_{N} q
$$

Using equations (13) and (14) yields:

$$
\frac{w_{N}-p}{q}=\frac{\eta_{N}}{\eta_{N}+\eta_{T}+\frac{1}{\theta}}-\alpha_{T} \quad, \quad \text { and }
$$

$$
\frac{w_{T}-p}{q}=\frac{-\eta_{T}}{n_{N}+\eta_{T}+\frac{1}{\theta}}+\alpha_{N}
$$

As may be seen from equations (15)-(16) the intermediate-run effects of changes in the real exchange rate on the two consumption wages are ambiguous due 
to the usual index-numbers problem. In the extreme case, however, with sufficiently low values of $\theta$, a rise in $q$ must lower the consumption wage in the nontradable goods sector and must raise the consumption wage in the tradable goods sector.

III. The Short Run

The foregoing analysis determined the equilibrium adjustment of the real exchange rate and of sectorial wages in response to an exogenous change in aggregate demand. The analysis pertained to the intermediate run in which labor contracts are rewritten. As indicated earlier we distinguish between the short run and the intermediate run. This distinction reflects labor market conditions. Specifically, it is assumed that due to cost of negotiations there are labor market contracts that set nominal wages in advance of the realization of the stochastic shocks. According to the contracts, employers can choose the quantity of labor services at the prevailing wage. [See, for example, Gray (1976), Fischer (1977), Hall and Lazear (1984)]. Accordingly, we define the short run as the run during which nominal wages are given by the prevailing contract.

In the short run employment is demand-determined. Therefore, equation (6) may not be used to determine the short-run changes in the employment of labor services and, thereby, in the supply of non-tradable goods. In order to determine these short-run changes we first note that the demand for labor in the non-tradable goods sector is governed by the real product wage $W_{N} / P_{N}$ which, in turn, can be written as $\left(W_{N} / S P_{T}^{*}\right)\left(P_{T} / P_{N}\right)$ where $P_{T}^{*}$ denotes the exogeneously given foreign price of tradeable goods and where $P_{T}=S P_{T}^{*}$ by the law of one price applicable to internationally tradable goods. Since in the short-run $W_{N}$ is given, it follows that the demand for labor services in the non-tradable goods sector can be 
written as $\mathrm{L}_{\mathrm{N}}^{\mathrm{d}}\left(\frac{\mathrm{P}_{\mathrm{T}} / \mathrm{P}_{\mathrm{N}}}{\mathrm{SP}_{\mathrm{T}}^{*}}\right)$. It is assumed that the nominal wage is set in advance at the level that is expected to clear the labor market. Thus, given the nominal wage, further changes in the demand for labor during the period of the contract (i.e., in the short run) can arise from unexpected changes in the realized real product wage. Since the foreign price of tradable goods, $P_{T}^{*}$, is assumed to be given, the percentage change in $L_{N}^{d}$ is

$$
\ell_{N}^{S R}=\sigma_{N}\left(s-q_{S R}\right)
$$

where $\sigma_{N}$ denotes the (absolute value of the) elasticity of the demand for labor with respect to the real product wage in the non-tradable goods sector, $s$ and $q$ denote the unexpected changes in the nominal and the real exchange rates (relative to the levels assumed when the nominal wage was set) and where SR denotes the short run. Using the production function, the change in the level of output of non-tradable goods corresponding to the change in labor input is

$$
x_{N}^{S R}=\beta_{N} \sigma_{N}\left(s-q_{S R}\right)
$$

Analogously, in the tradable-goods sector, the percentage changes in the demand for labor services and in the level of output are

$$
\ell_{T}^{S R}=\sigma_{T} S
$$

and

$$
\text { (10'1) } \quad \mathrm{x}_{\mathrm{T}}^{\mathrm{SR}}=\beta_{\mathrm{T}} \sigma_{\mathrm{T}} \mathrm{S} \quad \text {. }
$$

Substituting (10') for $\mathrm{x}_{\mathrm{N}}$ into (9) and using (11) yields 
$(9+1)$

$$
\psi+\lambda_{N}^{P} \xi q_{S R}=\beta_{N} \sigma_{N}\left(s-q_{S R}\right)
$$

Solving for the short-run value of q yields

$\left(12^{\prime}\right)$

$$
q_{S R}=-\frac{\psi-\beta_{N} \sigma_{N} s}{\lambda_{N}^{P}{ }^{P}+\beta_{N} \sigma_{N}}
$$

Equation $\left(12^{\prime}\right)$ reveals that in addition to its dependence on the exogenous demand shock, $\psi$, the short-run value of $q$ depends positively in the (unexpected) nominal exchange-rate policy. As seen in equation ( $9 \prime \prime)$, given an initial real exchange rate, an unexpected devaluation (i.e., a positive value of $s$ ), increases the supply of non-tradable goods by ${ }^{\beta}{ }_{N}{ }^{\sigma}{ }_{N}$ without altering the demand. ${ }^{5}$ The resulting excess supply is eliminated by a rise in $q$. It is noteworthy that in the special case for which the authorities follow a fixed exchange-rate policy (or, more generally, in the case for which the authorities maintain the preannounced path of the nominal exchange rate) so that $s=0$, an exogeneous reduction in the demand for non-tradable goods (a negative $\psi$ ) implies from equations (12) and (12') that the short-run real exchange rate $r$ ises and that $0 \leq q_{S R} \leq q$ (where $q$ denotes the intermediate-run change in the real exchange rate). These (weak) inequalities imply that following the short-run rise in the real exchange rate (consequent on an exogeneous decline in the demand for non-tradable goods), the real exchange rate exhibits a further $r$ ise in the intermediate run (consequent on the reopening of wage contracts).

Associated with the equilibrium values of the real exchange rate there are equilibrium intersectorial allocations of labor inputs and commodity outputs. In the intermediate run the levels of output are linked through the commodity production possibility frontier. On the other hand, in the short run, for the 
given contractual nominal wages, the levels of output are determined by the sectorial demands for labor.

In order to determine the short run output effects of the rise in the real exchange rate we recall from equations (10') and (10'') that for a fixed nominal exchange rate the supply of non-tradable goods changes by $-\beta_{N} \sigma_{N} q_{S R}$ and the supply of tradable goods is unchanged. Using equations (16)-(17) for the short and the intermediate-run real exchange rates it can be shown that

$\mathrm{x}_{\mathrm{N}}^{\mathrm{SR}} \leq \mathrm{x}_{\mathrm{N}} \leq 0=\mathrm{x}_{\mathrm{T}}^{\mathrm{SR}} \leq \mathrm{x}_{\mathrm{T}} \quad$ (where $\mathrm{x}_{\mathrm{N}}$ and $\mathrm{x}_{\mathrm{T}}$ denote the intermediate-run changes in the outputs on non-tradable and tradable goods, respectively).

A comparison between the intertemporal changes in commodity outputs and the corresponding changes in the real exchange rate reveals that the intermediate-run changes in output exhibit the typical positive association between the relative price of a commodity and its supply. This positive association reflects the fact that the economy operates along its production possibility frontier. On the other hand, this association does not prevail in the short run. Thus, the short-run supply of non-tradable goods is lower than the intermediate-run supply even though its relative price (the inverse of the real exchange rate) is higher. This lack of a positive association between the short-run relative price of non-tradable goods and their supply reflects the fact that in the short run, with a fixed nominal exchange rate, the economy does not operate along its production possibility frontier.

IV. The Optimal Adjustment of Nominal Wages

In this section we analyze the characteristics of optimal wage adjustment. The need for nominal wage adjustment arises from the realization of the stochastic 
shocks. In the absence of wage adjustment the prevailing labor-market contracts result in some stickiness of wages as in Gray (1976) and Fischer (1977).

Optimal wage adjustment yields a short-run equilibrium that replicates the performance of an economy in which labor markets clear without the constraints imposed by the existence of nominal wage contracts. By definition, such an equilibrium obtaines in the intermediate run in which (due to the opening of nominal wage contracts) the equilibrium structure of real wages is independent of the prevailing (short-run) contractual nominal wage. In our framework, optimal wage adjustments generate a short-run distribution of real wages which coincides with the distribution obtained in the intermediate run.

In what follows we consider two alternative formulations of wage-adjustment rules. The first relates changes in nominal wages to nominal exchange-rate policies and to the exogenous change in aggregate demand; the second relates the optimal wage adjustment to the nominal exchange-rate policy and to the change in the price level.. In order to compute the precise value of the equilibrium nominal wages we note that $p=s-\alpha_{N} q$ where $p$ denotes the intermediate-run change in the price level. Substituting into equation (15)-(16) and using equation (12) for the real exchange rate, $q$, yields

$$
w_{N}=s+b_{N} \psi
$$

$$
w_{T}=s+b_{T} \psi
$$

where

$$
b_{N}=\frac{\alpha_{T} \sigma+\theta \alpha_{N}}{\lambda_{N} p_{N}\left(\theta+\alpha_{T} \sigma\right)+\beta \sigma \theta \alpha_{T}}>0 \quad ; \quad b_{T}=\frac{\theta \alpha_{N}}{\lambda_{N}^{p_{j}} \xi\left(\theta+\alpha_{T} \sigma\right)+\beta \sigma \theta \alpha_{T}}>0
$$


Equations (17)-(18) specify the optimal rules for short-run nominal-wage adjustments as functions of the unanticipated nominal exchange rate policy (s) and the exogeneous change in aggregate demand for non-tradable goods $(\psi)$. The key characteristics of the optimal rule lies in the separation between the optimal adjustment of wages to nominal shocks (to which the optimal elasticity is unity) and the corresponding adjustment to real shocks (to which the optimal elasticity differs from unity). The elasticities $b_{N}$ and $b_{T}$ of nominal wages with respect to the exogeneous change in demand differ across sectors. Specifically, $b_{N}$ exceeds $b_{T}$ and the difference between these two elasticities increases with the of openness of the economy (as measured by the relative share $\alpha_{T}$ ). Further, the difference between $b_{N}$ and $b_{T}$ diminishes as the degree of homogeneity of relative skills rises. At the limit, with $\theta=\infty$, the two elasticities coincide and $\mathrm{b}_{\mathrm{N}}=\mathrm{b}_{\mathrm{T}}=\alpha_{\mathrm{N}} /\left({ }_{\mathrm{N}}^{\mathrm{p}} \xi+\beta \sigma \alpha_{\mathrm{T}}\right)$. As may be seen, in that case the elasticities decline with the degree of openness. At the limit, as $\theta$ approaches infinity and $\alpha_{T}$ approaches unity (while $\alpha_{N}$ approaches zero), the magnitude of these elasticites approaches zero. Finally, it is noteworthy that at the other extreme, with $\theta=0$, $b_{T}=0$ and $b_{N}=1 / \lambda_{N}^{p_{F}}$. In general, the difference between $b_{N}$ and $b_{T}$ reflects the fact that with heterogeneous distribution of relative skills an exogeneous change in the demand for non-tradable goods necessitates a change in the intersectorial relative wage.

In order to gain further insight into the interdependencies among the optimal values of the elasticities $b_{N}$ and $b_{T}$, the degree of openness (as measured by $\alpha_{T}$ ) and the heterogeneity of the distribution of relative skills (as measured by $\theta$ ) we first derive the functional relation between $b_{N}$ and $b_{T}$. Using the definitions of these elasticities (from equation (18)) it can be shown that 6 


$$
\mathrm{b}_{N}=\frac{1}{\lambda_{N}^{p_{\xi}}}-\frac{\alpha_{T}}{\alpha_{N}}\left(\frac{\lambda_{N}^{p}{ }^{p}+\beta \sigma}{\lambda_{N}^{p} \xi}\right) b_{T}
$$

The information conveyed by equation (24) is summarized in Figure 3 . In that figure the negatively sloped $A B$ schedule characterizes the relation between the optimal values of $b_{N}$ and $b_{T}$. The slope of this schedule depends on the degree of openness $\left(\alpha_{\mathrm{T}}^{0}\right)$. The steeper schedule, $\mathrm{AC}$, corresponds to a higher degree of openness $\left(\alpha_{\mathrm{T}}^{1}\right)$. For a given degree of openness the position of the equilibrium along tine negatively sloped schedule depends on the heterogeneity of the distribution of relative skills as measured by $\theta$. For example if $\alpha_{T}=\alpha_{T}^{\circ}$ and $\theta=0$, the optimal combination of $b_{N}$ and $b_{T}$ is at point $A$ (along the vertical axis), and if $\alpha_{\mathrm{T}}=\alpha_{\mathrm{T}}^{\circ}$ and $\theta=\infty$, the optimal combination is at point $\mathrm{B}$ (along the $45^{\circ}$ line). A $r$ ise in the value of $\theta$ moves the optimal combination of $b_{N}$ and $b_{T}$ towards point $B$ along the $A B$ schedule. 7

As is evident, the intermediate-run equilibrium is independent of the nominal exchange rate. Since the optimal short-run policy aims at replicating the equilibrium of the intermediate run, it follows that in the present framework the equilibrium real exchange rate and the equilibrium relative nominal wage can be obtained for any nominal exchange-rate policy. 8 Therefore, the optimal nominal exchange-rate policy must be determined on the basis of additional considerations that reflect concern with the levels of nominal wages or prices. Such considerations may reflect concerns with the short-run distribution of income (the analysis of which is provided in the Appendix), or some constraints on feasible price and wage adjustment. 9

The foregoing analysis showed that optimal wage policies result in realwage changes which differ across sectors. Optimal policies generate equilibrium sectorial changes in the product wage, as specified by equations (13)-(14), as 


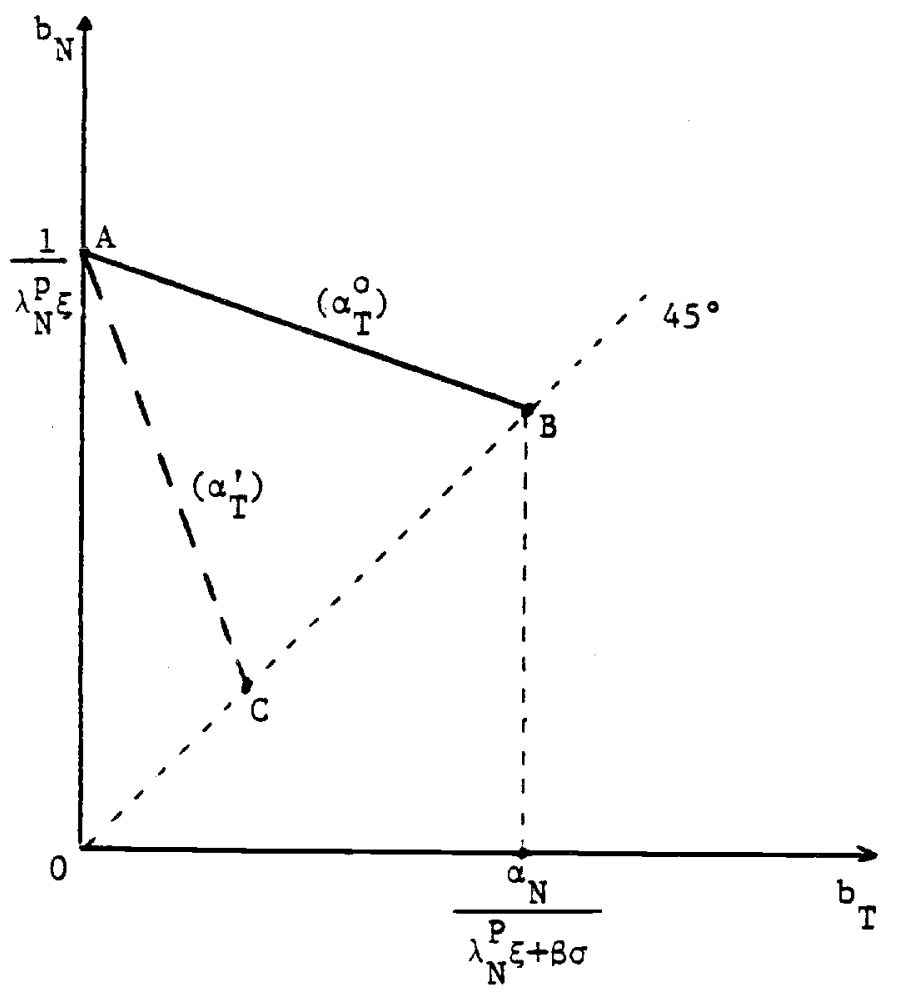

Figure 3: Optimal Adjustments of Nominal Wages and the Degree of Openness. 
well as equilibrium sectorial changes in the consumption wage, as specified by equations (15)-(16). The key point is that the equilibrium necessitates changes In both the ratio of sectorial nominal wages $\left(W_{N} / W_{T}\right)$ and the ratio of commodity prices $\left(\mathrm{P}_{\mathrm{T}} / \mathrm{P}_{\mathrm{N}}\right)$--the real exchange rate. Attainment of these two targets requires two (independent) instruments. This perspective suggests that nominal exchangerate policy alone cannot succeed in generating the necessary short-run wage adjustments since it does not alter the ratio of nominal wages. 10

It is important to emphasize, however, that equality between the number of policy targets and instruments is a necessary but not a sufficient condition for the attainment of a given set of policy goals. In terms of our formulation, as long as the structure of relative nominal wages is given there is no set of policy instruments that can yield the target of an undistorted equilibrium. As an 11 lustration of this general principle we note that even though a proper combination of fiscal and exchange-rate policies may be used in order to obtain a desired level of aggregate employment and output mix, there is no way that such policies can be used to eliminate labor-market distortions induced by a fixed nominal-wage structure. 11

\section{Concluding Remarks}

In this paper we analysed the implications of a reduction in the demand for domestic goods on the short-run and the intermediate-run values of the real exchange rate, the composition of output, real wages and the sectorial allocation of employment; the Appendix analyses the effects on the functional distribution of income. While the reason for the exogeneous decline in demand was not specified explicitely, it could be interpreted as part of a stabilization program or as a response to an exogenous decline in current or prospective flows of foreign aid. 
One of the typical characteristics of an economy in need for a drastic reduction in aggregate demand is a distorted structure of wages. Such a distortion manifests itself in both the relative intersectorial wages and the absolute levels thereof. In order to provide for a meaningful analysis of intersectorial wage differentials without abandoning the main tenets of the competitive-neoclassical paradigm, we allowed for heterogeneous distribution of skills.

In our framework, labor-market contracts in each sector stipulate the nominal-wage rule for the length of the contract period. The existence of contracts and the length of the contract period reflect the cost of negotiations. We showed that nominal exchange-rate policies alone can not succeed in alleviating the undersirable consequences of the short-run stickiness of nominal wages. The cost of a distorted structure of wages can be eliminated only through a proper adjustment of both the absolute and the relative nominal-wage structure. Our analysis provided the precise formulae for the optimal intersectorial wage adjustment.

Rather than summarizing the results we outline in what follows some of the limitations and further extensions. Our analysis did not attempt to contribute to the growing body of literature on the theory of wage contracts. Rather, the form of the wage contract was taken as a stylized description of typical labor-market conventions. Implicit in the formulation was the assumption that employers and employees are risk neutral and, therefore, the existing contracts reflect only the cost of negotiations. A useful extension would allow for risk aversion. With risk aversion the existence of contracts could be rationalized in terms of the insurance function.

Another extension would model explicitely the dynamic linkages between the intermediate run and the long run, and would incorporate explicitely the process of investment in human capital within a capital-theoretic framework. A more 
elaborate extension would recognize that in the long run there are no sectorspecific factors of production and the transition towards the long run includes reallocation and accumulation of both human and material capital. Furthermore, throughout the analysis we have assumed that the economy faces a once and for all permanent shock. An extension which allows for transitory shocks would yield dynamic paths of adjustments that depend critically on whether the shocks are perceived as permenent or transitory.

Further, in our framework, the welfare loss arises only from a sub-optimal wage distribution. Implicit in this specification is the assumption that except for the labor market all other markets are undistorted. A useful extension would provide for a richer formulation of the welfare cost arising from sub-optimal money holdings, and would allow for the manifestation of the services of money and for the erosion of these services as a result of the inflationary process.

Finally, in focusing on the relation between government spending and the key economic variables, we have not dealt with the important issues related to government finance. A more complete treatment would specify the means of public finance along with the specification of government outlays. 
APPENDIX

The Distribution of Income

In this Appendix we determine the effects of nominal and real exchange-rate changes on the functional distribution of income. Since short-run changes in the distribution of income differ from the corresponding intermediate-run changes, their analysis provides insights into the formation of interest groups lobbying for policy measures. We start with the intermediate run.

\section{A. The Intermediate Run}

Equations (13)-(16) in section II showed the effects of real exchange-rate changes on the intermediate-run values of equilibrium product and consumption wages. Here we compute the analogous expressions for the returns to the sectorspecific capital. In order to simplify the exposition we will assume that the production functions are of the Cobb-Douglas variety, and we denote the elasticities of outputs of non-tradable and tradable goods with respect to the corresponding labor inputs by $\beta_{N}$ and $\beta_{T}$, respectively. Since capital is assumed to be specific, the percentage change in the return to capital owners in each sector can be measured by the percentage change in total capital income in the corresponding sector. Accordingly, denoting the return to capital in the non-tradable goods sector by $R_{N}$ so that $R_{N}=P_{N} X_{N}-W_{N} L_{N}$, it can be shown that the percentage change in the real return to capital, $R_{N} / P$ (to be denoted by $\left(r_{N}-p\right.$ )) equals $\beta_{N} \ell_{N}-\alpha_{T} q$. Thus, using equation (6) for $\ell_{N}$, the elasticity of $R_{N} / P$ with respect to the real exchange rate is 
$(A-1) \quad \frac{r_{N}-p}{q}=\frac{-\beta_{N}}{n_{N}+n_{N}+\frac{1}{\theta}}-a_{T}<0$.

Similarly, it can be shown that $\left(r_{T}-p\right)$ equals $B_{T} \ell_{T}+\alpha_{N} q$, which (for movements along the labor transformation curve) is also equal to $-\left(\phi_{N}^{L} / \phi_{T}^{L}\right) B_{T}{ }_{N}+\alpha_{N} q$. In this expression $\phi_{N}^{L}$ denotes the fraction of the total wage bill that accrues to labor employed in the non-tradable goods sector and $\phi_{T}^{L}=1-\phi_{N}^{L}$ denotes the corresponding share that accrues to labor employed in the tradable goods sector. Therefore, using equation (6) for $d_{N}$, the elasticity of the real return to capital in the tradable-goods sector with respect to the real exchange rate is

$(A-2)$

$$
\frac{r_{T}-p}{q}=\frac{\left(\phi_{N}^{L} / \phi_{T}^{L}\right) \beta_{T}}{n_{N}+n_{T}+\frac{1}{\theta}}+\alpha_{N}>0
$$

The formulation in equations $(A-1)-(A-2)$ reveals that the extent of the change in the returns to capital depends on the heterogeneity of the distribution of skills. At the extreme, with $\theta=0$, labor is also fully sector specific. In that case the percentage change in the product wage in each sector exactly equals the percentage change in the return to capital in that sector.

The elasticity of the wage ratio $\mathrm{W}_{\mathrm{N}} / \mathrm{W}_{\mathrm{T}}$ with respect to the real exchange rate is found by subtracting equation (15) from equation (16), and the elasticity of the ratio of the returns to the two types of capital $R_{N} / R_{T}$ with respect to the real exchange rate is found by subtracting equation (A-2) from (A-1). These elasticities are

$(A-3)$

$$
\frac{r_{N}-r_{T}}{q}=-q-\frac{B_{N}+\left(\phi_{N}^{L} / \phi_{T}^{L}\right) B_{T}}{n_{N}+n_{T}+\frac{1}{\theta}}<-q<\frac{w_{N}-w_{T}}{q}=-\frac{1}{\theta\left(n_{N}+n_{T}\right)+q}<0 .
$$


In order to compare the percentage changes in the sectoral wage-rental ratios we subtract equation $(A-9)$ from (15) and equation (A-2) from (16):

$(A-4) \quad \frac{\mathrm{w}_{\mathrm{N}}-\mathrm{r}_{\mathrm{N}}}{\mathrm{q}}=\frac{\mathrm{q}}{\eta_{\mathrm{N}}+\eta_{\mathrm{T}}+\frac{1}{\theta}}>0>\frac{\mathrm{w}_{\mathrm{T}}-\mathrm{r}_{\mathrm{T}}}{\mathrm{q}}=\frac{-\left(\phi_{\mathrm{N}}^{\mathrm{L}} / \phi_{\mathrm{T}}^{\mathrm{L}}\right)}{\eta_{\mathrm{N}}+\eta_{\mathrm{T}}+\frac{1}{\theta}}$.

Thus, except for the special case for which $\theta=0$, a change in the real exchange rate impacts on the relative returns to labor and capital in each sector.

In summary, these results (along with those in equations (13)-(14) of the text) can be combined to yield the chain of inequalities. In equation (A-5) which also indicates the intermediate-run changes in the functional distribution of income: .

$(A-5)$

$$
r_{N}<p_{N}<w_{N}<w_{T}<p_{T}<r_{T} \quad(\text { for } q>0, \theta>0) \quad .
$$

These inequalities are reversed for the case in which $q>0$.

B. The Short Run

We turn now to analyse the short-run effects of changes in the real exchange rate on wages and on the return to capital. In the short run, due to contracts, the nominal wage is given and, therefore, the percentage changes in the product wages are

$(A-6)$

$$
w_{T}-p_{T}=-s
$$

$(A-7)$

$$
w_{N}-p_{N}=\left(w_{N}-p_{T}\right)+\left(p_{T}-p_{N}\right)=-s+q_{S R}
$$


Equations $(A-6)-(A-7)$ show that these changes depend on the value of $s$ which reflects the short run nominal exchange-rate policy. We note that if the authorities maintain a fixed exchange rate so that $s=0$, then the product wage in the tradable goods sector does not change.

The short-run effects of the change in the real exchange rate on the real wages measured in terms of the consumption basket are

$$
w_{N}-p=-p=-s+\alpha_{N} q_{S R}
$$

$(A-9)$

$$
w_{T}-p=-p=-s+\alpha_{N} q_{S R}
$$

Thus, with $s=0$ the elasticities of the consumption wage with respect to the real exchange rate are positive and equal to $\alpha_{N}$. This short-run result should be compared with the corresponding intermediate-run results (reported in equations (15) $-(16)$ of the text), where we saw that the intermediate-run effects of changes in the real exchange rate on real wages were ambiguous. This comparison between the short run and the intermediate-run results has implications concerning the likelihood of the formation of interest groups lobbying for policy measures. specifically, while the interest of labor (as measured in terms of the direction of changes in real wages) coincides across sectors in the short run, these interests may diverge in the intermediate run. We proceed in analyzing the short-run effects of the changes in the real exchange rate on the return to capital. Recalling that $r_{N}-p=\beta_{N} \ell_{N}-\alpha_{T} q$, we use equation (6') for the short-run value of $\ell_{N}$ and substitute $\left(1 / \eta_{\mathrm{N}}\right)$ for $\sigma_{\mathrm{N}}$ in order to obtain:

$$
(A-10) \quad \frac{r_{N}-p}{q}=\frac{\beta_{N}}{n_{N} q} s-\frac{\beta_{N}}{n_{N}}-\alpha_{T} \text {. }
$$


Analogously, recalling that $r_{T}-p=-\left(\phi_{N}^{L} / \phi_{T}^{L}\right) \beta_{T} l_{N}+\alpha_{N} q$, the short-run elasticity of the real return to capital in the tradable-goods sector is

(A-11) $\quad \frac{r_{T}-p}{q}=\frac{\left(\phi_{N}^{L} / \phi_{T}^{L}\right) \beta_{T}}{\eta_{T} q} s+\alpha_{N}$.

Equations $(A-90)$ and $(A-91)$ show that, analogously with the effects on the real wages, the short-run real returns to capital depend on the nominal exchange rate policy. For the case in which $s=0$, the elasticity of ${ }^{R} / P$ with respect to the real exchange rate is negative whereas the corresponding elasticity of $\mathrm{R}_{\mathrm{T}} / \mathrm{P}$ is positive. Furthermore, with $s=0$ we note by comparing equations $(A-10)-(A-11)$ with $(A-1)-(A-2)$ that the (algebreic value of the) intermediate-run elasticities of the real returns to capital with respect to the real exchange rate exceed the corresponding short-run values.

The foregoing analysis determined the short-run effects of real exchange rate changes on real wages and on the returns to capital in each sector. Since by assumption the stock of capital employed in each sector is given, knowledge of changes in rental rates is sufficient for determining total income to capital owners. In contrast, since the employment of labor need not be fixed, the computation of the wage bill requires that we supplement our analysis of changes in the real wage with a corresponding analysis of the changes in the level of employment. To simplify the exposition we will assume that $\beta_{N}=\beta_{T}=B .12$

The real wage bill is $\left(W_{N} L_{N}+W_{T} L_{T}\right) / P$. Using the fact that with equal sectoral labor intensities $\phi_{\mathrm{N}}^{\mathrm{L}}=\alpha_{\mathrm{N}}$ and $\phi_{\mathrm{T}}^{\mathrm{L}}=\alpha_{\mathrm{T}}$, the percentage change in the wage bill is $\alpha_{\mathrm{N}} \ell_{\mathrm{N}}+\alpha_{\mathrm{T}} \ell_{\mathrm{T}}-\mathrm{p}$. From equation (6') and (6") the percentage changes in the levels of employment in the non-tradable and in the tradable goods sector are 
$\sigma\left(s-q_{S R}\right)$ and $\sigma s$, respectively. Substituting these expressions for $\ell_{N}$ and $\ell_{T}$, recalling that $p=s-\alpha_{N} q$ and that $\sigma-1=\beta \sigma$, yields

$(A-12)$

$$
\alpha_{N} \ell_{N}+\alpha_{T} \ell_{T}-p=\beta \sigma\left(s-\alpha_{N} q_{S R}\right)=\beta \sigma p
$$

Equation $(A-12)$ shows that the short run change in the real wage bill depends positively on the change in the price index. The change in the price, in turn, depends on both the nominal and the real exchange-rates. Ceteris paribus, a higher real exchange rate lowers $p$, and a higher nominal exchange rate raises $p$. Thus, for the case in which $s=0$, the real wage bill falls when the real exchange rate rises. This result is of some interest in view of our previous analysis of the short-run changes in the consumption wages. As shown in equations $(A-8)-(A-9)$ a higher value of the real exchange rate raises the consumption wage in both sectors by an elasticity of $\alpha_{N}$. The result in equation (A-12) implies that the

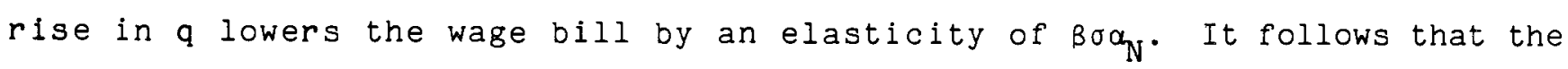
level of utilization of labor declines by an elasticity of $(1+\beta \sigma) \alpha_{N}=\sigma \alpha_{N} \cdot 13$ Finally we note that in the special case for which the price index is unchanged so that $p=0$, real consumption wages as well as the wage bill do not change and, therefore, in that special case the level of aggregate labor input remains unchanged. In general, however, unexpected changes in the nominal exchange rate alter the price level; it impacts on the level of aggregate labor utilization by an elasticity that is equal to $\sigma$. Such short-run changes in aggregate employment level may also serve as an important determinant of the formation of interest groups. Since in the intermediate run the level of aggregate employment remains unchanged, differences between the short and the intermediate-run levels of aggregate employment may also be responsible for the changes in the composition of interest groups that take place over time. 


\section{Footnotes}

'Formally, let the density function of skills be $\mathrm{f}\left(\mathrm{L}_{\mathrm{N}}, \mathrm{L}_{\mathrm{T}}\right)$. This function measures the number of workers whose skills can yield labor services $\left(\mathrm{L}_{\mathrm{T}}, \mathrm{L}_{\mathrm{N}}\right)$. The total supply of labor services to each sector at the given wage ratio $\left(W_{N} / W_{T}\right)_{0}=w_{0}$ is

$$
\begin{aligned}
& \mathrm{L}_{T}^{0}=\int_{0}^{\infty}\left[\int_{\omega_{0} L_{N}}^{\infty} f\left(L_{N}, L_{T}\right) L_{T} d L_{T}\right] d L_{N} \\
& L_{N}^{0}=\int_{0}^{\infty}\left[\int_{0}^{\omega_{0}^{L} N} f\left(L_{N}, L_{T}\right) L_{N} d L_{T}\right] d L_{N} \quad .
\end{aligned}
$$

In terms of Figure, the integration limit $\omega_{\mathrm{O}} \mathrm{L}_{\mathrm{N}}$ indicates the skill level $\mathrm{L}_{\mathrm{T}}$ of a marginal worker. For example, if the marginal worker is worker $c$ then for him $\mathrm{L}_{\mathrm{N}}=\mathrm{L}_{\mathrm{N}}^{\mathrm{c}}$ and, with a wage ratio $\omega_{0}, \mathrm{~L}_{\mathrm{T}}^{\mathrm{c}}=\omega_{\mathrm{O}} \mathrm{L}_{\mathrm{N}}^{\mathrm{c}}$. Thus, at the margin, a reallocation of workers between sectors implies that $\mathrm{dL}_{\mathrm{T}} / \mathrm{dL}_{\mathrm{N}}=-\omega_{0}$. This property is used in equation (3) below and can be derived formally by taking the ratio of the derivatives of $\mathrm{L}_{\mathrm{T}}^{\circ}$ and $\mathrm{L}_{\mathrm{N}}^{\circ}$ with respect to $\omega$.

${ }^{2}$ In principle the analysis could be extended to consider long run equilibrium where the long run is defined as the run during which workers have been allowed to acquire skills and, thereby, raise the value of $\theta$. In the limit, as the relative skill differentials narrows down, the value of $\theta$ approaches infinity and the labor transformation function becomes a straight line whose slope corresponds to the long-run equilibrium wage ratio. In this paper we focus on the short-run and on the intermediate-run and we do not analyse the dynamic evolution 
of the economy towards long-run equilibrium. The transition towards the long run can be described in terms of investments in human capital. For such formulations see Aizenman (1983) and Findlay and Kierzkowski (1983). A more complete analysis would also allow for the gradual transformation of all the specific fixed factors into variable mobile factors of production. For a formulation of the dynamics of specific physical capital see Mussa (1978, 1982a).

3 Formally, the link between the production possibilities frontier and the labor transformation function can be expressed in terms of the corresponding elasticities of substitution. For example, denoting the elasticities of substitution along the labor transformation function and along the production possibility frontier by $\sigma_{\mathrm{L}}$ and $\sigma_{\mathrm{X}}$, respectively, where $\sigma_{\mathrm{L}}=\mathrm{dlog}\left(\mathrm{L}_{\mathrm{T}} / \mathrm{L}_{\mathrm{N}}\right) / \mathrm{dlog}\left(\mathrm{W}_{\mathrm{T}} / \mathrm{W}_{\mathrm{N}}\right)$ and $\sigma_{X}=\operatorname{dlog}\left(X_{T} / X_{N}\right) / d \log \left(P_{T} / P_{N}\right)$, we get for the Cobb-Douglas case with equal sectoral labor shares $\sigma_{L}=\theta / \alpha_{T}$ and $\sigma_{X}=\beta /\left[1-\beta+\left(\alpha_{T} / \theta\right)\right]$ where $\alpha_{T}$ denotes the expenditure share of spending on tradable goods. Thus, $\sigma_{X}=\beta /\left[1-\beta+\left(1 / \sigma_{L}\right)\right]$. As is evident if $\theta=\infty, \sigma_{L}=\infty$ and $\sigma_{X}=\beta /(1-\beta)$.

${ }^{4}$ A richer formulation could also allow for the effects of real interest rates on spending as in Bruno (1976), Martin and Sellowsky (1981) and Dornbusch (1983). It is noteworthy, however, that the key conclusions of the present analysis do not depend upon the real interest rate effect; for such an extension see Aizenman and Frenkel (1985b).

${ }^{5}$ The assumption that the unexpected change in the nominal exchange rate does not alter the demand presumes that the value of wealth (or permanent income) is independent of $s$ and, therefore, $\psi$ does not change in response to $s$. More generally, as long as the marginal propensity to spend on non-tradable goods out of transitory income is smaller than unity, an unexpected devaluation creates an excess supply and results in a rise in $q$. 
${ }^{6}$ In deriving equation (19) we use a variant of the undetermined coefficients method. We start by postulating a linear relation $\mathrm{b}_{\mathrm{N}}=\mathrm{a}_{1}+\mathrm{a}_{2} \mathrm{~b}_{\mathrm{T}}$. We then substitute the definitions of $b_{N}$ and $b_{T}$ from equation (18), collecting terms and equating coefficients of corresponding variables, yields the value of the coefficients $a_{1}$ and $a_{2}$.As is seen, even though the optimal values of $b_{N}$ and $b_{T}$ depend on $\theta$, the functional relation between these elasticities is independent of $\theta$. This independence implies that changes in $\theta$ which may occur over time do not impact on the functional relation characterizing the optimal wage formulae. Therefore, this functional relation is independent of time.

${ }^{7}$ The optimal rules for short-run nominal-wage adjustments can also be cast in terms of indexation rules by which changes in nominal wages are indexed to changes in the nominal exchange rate and to changes in the price level. Such rules can be written as $w_{N}=a_{N}^{s}+a_{N}^{p}$ and $w_{T}=a_{T}^{s} s+a_{T}^{p} p$, where $a_{N}^{s}$ and $a_{T}^{s}$ denote the coefficients of indexation of nominal-wage adjustment to $s$, and where $\mathrm{a}_{\mathrm{N}}^{\mathrm{p}}$ and $\mathrm{a}_{\mathrm{T}}^{\mathrm{p}}$ denote the corresponding coefficients of adjustment to $\mathrm{p}$. It can be shown [see Aizenman and Frenkel (1985b) that the optimal coefficients are $a_{N}^{S}=-\left(\frac{\alpha_{T} \sigma}{\theta+\alpha_{T} \sigma}\right) \frac{\alpha_{T}}{\alpha_{N}}, \quad a_{N}^{p}=1+\left(\frac{\alpha_{T} \sigma}{\theta+\alpha_{T} \sigma}\right) \frac{\alpha_{T}}{\alpha_{N}}, \quad a_{T}^{s}=\frac{\alpha_{T} \sigma}{\theta+\alpha_{T} \sigma}$, and $a_{T}^{p}=\frac{\theta}{\theta+\alpha_{T} \sigma}$, As seen, the smaller is the value of $\theta$, the higher becomes the intersectoral difference between nominal wage adjustment rules. As $\theta$ approaches infinity, the optimal indexation of nominal wage adjustment to changes in the price level is unity whereas the corresponding coefficients of indexation to exchange rate changes is zero. Also a higher degree of openness is associated with a higher degree of optimal wage adjustment to changes in the nominal exchange rate.

${ }^{8}$ This can also be observed by reference to equations (17) and (18) which express the optimal wage adjustment as a function of the nominal exchange-rate policy (s) and the change in aggregate demand for non-tradable goods $(\psi)$. In that 
connection it is seen that different values of $s$ do not alter the equilibrium ratio of nominal wages.

${ }^{9}$ For example, suppose that institutional constraints prevent a reduction in nominal wages. In that case nominal exchange-rate policy must accompany the fall in demand (i.e. $\psi(0)$ ). Specifically, equations (17)-(18) imply that in order to keep the nominal wage in the non-tradable goods sector unchanged, the fall in demand which governs the value of $\psi$ must be accompanied by a devaluation so that $s+b_{N} \psi=0$. In that case the nominal wage in the tradable-goods sector $r$ ises by $\left(b_{T}-b_{N}\right) \psi$. Alternatively, suppose that the authorities wish to neutralize the price-level consequences of the policies. Since in general $p=s-\alpha_{N} q$, it follows that in order to stabilize the price level, the package of optimal policies should include a devaluation so that $s=\alpha_{N} q$. This devaluation must be accompanied by changes in nominal wages in order to generate a stable price. A package of optimal policies which includes a devaluation yielding a stable price, must lower the nominal wage in the non-tradable goods sector and raise the nominal wage in the tradable goods sector. The precise wage adjustemnts can be read form the wage equations in footnote 7 for $p=0$.

10 The only circumstance under which nominal exchange-rate policy alone can yield optimal short-run equilibrium arises when the distribution of relative skills is homogeneous ( $i . e$. , when $\theta=\infty$ ). In that case relative nominal wages are always constant and are independent of the real exchange rate. In this special case as shown in Aizenman and Frenkel (1985a, 1985c) wage indexation rules bear an exact dual relation to monetary policy rules. In the more general case as shown by Blinder and Mankiw (1984) and as illustrated in the present paper aggregative policies (like monetary policy or nominal exchange rate policy) are not suitable for dealing with sector-specific shocks. For a related analysis of optimal policies in the presence of firm-specific shocks see Marston and Turnovsky (1985). 
11 For a detailed analysis of the interactions among fiscal policies, exchange-rate policies and the output mix see Aizenman and Frenkel (1985b) where it is shown that for a given nominal wage structure, the ratio of commodity outputs depends uniquely on the real exchange rate whereas the aggregate level of employment depends uniquely on the price level (and thereby on the nominal exchange rate); hence, as long as $\theta<\infty$, fiscal and exchange-rate policies may be use to yield a desired employment level and output mix.

12 With this simplification $\sigma_{T}=\sigma_{N}=\sigma=1 /(1-\beta)$, and the values of the expenditure shares on the two goods equal the corresponding shares of the sectoral laborincome in total wage bill. Thus, $\alpha_{\mathrm{N}}=\phi_{\mathrm{T}}^{L}$ and $\alpha_{\mathrm{T}}=\phi_{\mathrm{T}}^{L}$. This simplification allows us to abstract from issues arising from intersectoral differences in relative labor intensities and to focus on issues arising from short-run nominal contracts and intermediate-run heterogeneity of the distribution of relative skills. With our assumption, the long-run concavity of the production possibility frontier arises only due to the diminishing marginal productivities of labor in the presence of the sector-specific capital. In the absence of sector-specific capital the assumption that $\beta_{\mathrm{N}}=\beta_{\mathrm{T}}$ implies that when $\theta=\infty$, the production possibility frontier is a straight line.

13 It is relevant to reemphasize that due to the heterogeneity of the distribution of relative skills, the concept of employment (as measured by the number of workers) differs from the concept of labor input (as measured by labor services). In our case, with Cobb-Douglas production functions and with equal sectoral factor shares, the composite index of labor input can be defined as $\left(W_{N} L_{N}+W_{T} L_{T}\right) /\left(W_{N}^{\alpha} N_{W_{T}}{ }^{\alpha}\right)$ 


\section{REFERENCES}

Aizenman, Joshua. "Dynamies of Trade Liberalization Policy," Journal of Development Economics 13, no. 1-2 (August/October 1983): 133-42. Aizenman, Joshua and Frenkel, Jacob A. (1985a). "Optimal Wage Indexation, Foreign Exchange Intervention and Monetary Policy," American Economic Review 75, No. 3 (June 1985): 402-23.

(1985b). "Real and Nominal Exchange Rates, Fiscal Policies and the Wage Structure," presented at a conference on "The Foreign-Exchange Rate in Inflation and Stabilization," sponsored by the Aron and Michael Chilewich Chair in International Economics at the Hebrew University of Jerusalem, Israel June 1985.

(1985c). "Supply Shocks, Wage Indexation and Monetary Accommodation," NBER Working Paper, No. 1609, April 1985..

Blinder, Alan S and Mankiw, Gregory N. "Aggregation and Stabilization Policy in a Multi-Contract Economy," Journal of Monetary Economics 13, No. 1 (January 1984): 67-86.

Brecher, Richard A. "Minimum Wage Rates and the Pure Theory of International Trade", Quarterly Journal of Economics 88, No. 1 (February 1974): 98116.

Bruno, Michael. "The Two-Sector Open Economy and the Real Exchange Rate," American Economic Review 66, No. 4 (September 1976): 566-77.

Dornbusch, Ruidger. "Real Interest Rates, Home Goods, and Optimal External Borrowing," Journal of Political Economy 99, No. 9, (February 1983): $949-53$. 
Findlay Ronald and Kierzkowski, Henryk. "International Trade and Human Capital: A Simple General Equilibrium Model, "Journal of Political Economy 91, No. 6, (December 1983): 957-78.

Fischer, Stanley. "Long Term Contracts, Rational Expectations and the Optimal Policy Rule," Journal of Political Economy 85, No. 1, (February 1977): 191-205.

Gray JoAnna. "Wage Indexation: A Macroeconomic Approach," Journal of Monetary Economics 2, No. 2 (April 1976): $231-46$.

Hall, Robert E. and Lazear, Edward P. "The Excess Sensitivity of Quits and Layoffs to Demand," Journal of Labor Economics 2, No. 2 (April 1984): 233-57.

Helpman, Elhanan. "Nontraded Goods and Macroeconomic Policy Under a Fixed Exchange Rate", Quarterly Journal of Economics 91, No. 3 (August 1977): 469-80.

Jones, Ronald W. "A Three Factor Model in Theory, Trade, and History" in Bhagwati, Jagdish N., ed.al. (eds.) Trade, The Balance of Payments, and Growth Amsterdam: North-Holland, 1971.

Marston, Richard C. "Real Wages and the Terms of Trade: Alternative Indexation Rules for an Open Economy," Journal of Money Credit and Banking 16 , No. 3 (August 1984): 285-301.

Marston, Richard C. and Turnovsky, Stephen J. "Macroeconomic Stabilization Through Taxation and Indexation: The Use of Firm-Specific Information," Journal of Monetary Economics, 16, No. 3 (November 1985): 375-95.

Martin, Ricardo and Selowsky, Marcelo. "Engery Prices, Substitution, and Optimal Borrowing in the Short Run An Analysis of Adjustment in Oil Importing Developing Countries." Unpublished manuscript, World Bank, February 1981. 
Mayer, Wolfgang. "Short-Run and Long-run Equilibrium for a Small open Economy," Journal of Political Economy 82, No. 5 (September/October 1974): $955-967$.

Mussa, Michael. "Tariffs and the Distribution of Income: The Importance of Factor Specificity, Substitutability, and Intensity in the Short and Long Run," Journal of Political Economy 82, No. 6 (November/December 1974): $1999-1203$.

- "Dynamic Adjustment in the Heckscher-Ohlin-Samuelson Model," Journal of Political Economy 86, No. 5 (October 1978): 775-91. (1982a). "Government Policy and the Adjustment Process" in Bhagwati, Jagdish N. (ed.) Import Competition and Response Chicago, II: University of Chicago Press, $1982 \mathrm{pp} .73-120$.

(1982b). "Imperfect Factor Mobility and the Distribution of Income," Journal of International Economics 12, No. 1 (February 1982): $125-41$.

Neary, Peter J. "Nontraded Goods and the Balance of Trade in a Neo-Keynesian Temporary Equilibrium", Quarterly Journal of Economics 95, No. 3 (November 1980): 403-29.

Rosen, Sherwin. "Substitution and Division of Labor," Economica 45 (179) (August 1978): 235-50.

Stolper, Wolfgang F. and Samuelson, Paul A. "Protection and Real Wages", Review of Economic Studies 9, (November 1941): 58-73. 